\title{
Aeroheating Characteristics for a Two-Stage-To-Orbit Concept During Separation at Mach 6
}

\author{
Derek S. Liechty* \\ NASA Langley Research Center, Hampton, VA 23681
}

\begin{abstract}
An experimental study was conducted to determine the proximity aeroheating characteristics for a two-stage-to-orbit concept in close proximity in the NASA Langley 20-Inch Mach 6 Air Tunnel. A new hybrid discrete thin-film resistance gauge technique was evaluated in this study and used to measure experimental interference heating levels between the booster and the orbiter at a constant freestream Reynolds number of $8.25 \times 10^{6} / \mathrm{m}$ and a variety of separation and axial offset distances. It was found that, as the orbiter separates from the booster and the booster falls away, the windward centerline heating increased on the orbiter by as much as 13-times over the baseline, single model heating distribution, and on the booster by as much as 6-times. The aeroheating database developed can be used for computational fluid dynamic code validation.
\end{abstract}

\section{Nomenclature}

$h \quad=$ heat transfer coefficient, $h=q /\left(H_{a w}-H_{w}\right),\left(\mathrm{kg} / \mathrm{m}^{2} / \mathrm{s}\right)$

$H \quad=$ enthalpy $(\mathrm{J} / \mathrm{kg})$

$L \quad=$ model reference length $(\mathrm{m})$

$p \quad=$ pressure $(\mathrm{Pa})$

$q \quad=$ surface heat transfer rate $\left(\mathrm{W} / \mathrm{m}^{2}\right)$

$R_{n} \quad=$ model reference nose radius $(\mathrm{m})$

Re $=$ unit Reynolds number $(1 / \mathrm{m})$

$T \quad=$ temperature $(\mathrm{K})$

$U \quad=$ velocity magnitude $(\mathrm{m} / \mathrm{s})$

$x \quad=$ axial distance from nose of model $(\mathrm{m})$

$y=$ spanwise distance from centerline of model $(\mathrm{m})$

$\alpha \quad=$ angle-of-attack (deg)

$\rho \quad=$ density $\left(\mathrm{kg} / \mathrm{m}^{3}\right)$

$\begin{array}{ll} & \\ \infty & =\text { Subscripts } \\ a w & =\text { adiabatic wall conditions } \\ F R & =\text { conditions from Fay-Riddell calculation for a hemisphere } \\ t 1 & =\text { reservoir conditions } \\ t 2 & =\text { stagnation conditions behind a normal shock } \\ w & =\text { wall conditions }\end{array}$

\footnotetext{
*Aerospace Technologist, Aerothermodynamics Branch, m/s 408A.
}

Copyright (C) 2005 by the American Institute of Aeronautics and Astronautics, Inc. The U.S. Government has a royaltyfree license to exercise all rights under the copyright claimed herein for Governmental purposes. All other rights are reserved by the copyright owner. 


\section{Introduction}

$\mathbf{N}^{\prime}$ ASA's Integrated Space Transportation Plan (ISTP) provided a comprehensive, long-term strategy to meet future launch vehicle and technology needs combined with reduced cost and improved safety and reliability. Given the technology levels in the areas of propulsion, structures, and materials, the technical risk for Single-StageTo-Orbit (SSTO) was high, and advanced Reusable Launch Vehicle (RLV) design attention shifted back to TwoStage-To-Orbit (TSTO) concepts. While TSTO concepts which were considered ranged greatly with respect to orbiter/booster shape, propulsion system characteristics, and resulting nominal flight trajectories, all TSTO configurations presented a critical need to enhance the aerodynamic and aerothermodynamic knowledge base in two-body separation characteristics within the sensible atmosphere to satisfy both nominal and abort ascent separation scenarios. The present work adds experimental aeroheating data at Mach 6 to the existing database of aerodynamic data presented in Ref. 1. This database of an orbiter and booster of comparable size in close proximity can be used as a computational fluid dynamics validation tool. A new hybrid thin-film resistance gauge technique was evaluated during the present study to measure aeroheating levels on vehicle surfaces where optical access is limited and the technique of phosphor thermography could not be used. While this effort was initiated to satisfy specific requirements in the former Next Generation Launch Technology (NGLT) program ${ }^{2}$, the tools and methodologies developed were generic in nature and may be applicable to a broad range of launch vehicles/architectures in NASA's new Space Exploration Initiative.

\section{Configuration Description}

The same generic two-stage configuration that was used in the aerodynamic study in Reference 1 was also used in the present study. The Langley Glide-Back Booster (LGBB), in a belly-to-belly, bimese configuration is shown in Fig. 1. The LGBB is a generic wing-body configuration that was developed by the Langley Research Center Vehicle Analysis Branch for in-house multi-stage launch vehicle system-analysis studies.

Figure 2 shows a detailed planform schematic of the LGBB. The full-scale configuration has an 2.09-m diameter cylindrical fuselage with a drooped, $0.28 \mathrm{~m}$ radius nose. The length from the tip of the nose to the base of the body (i.e. the engine exit plane) is $19.05 \mathrm{~m}$. The wing/strake is a NACA 2300 series airfoil at a 6-degree dihedral angle; the strake is swept 81.1-degrees and the wing is swept 45.3-degrees. The wing's forward swept trailing edge is a full span elevon pair separated by a center body flap. The configuration has a center vertical tail with a leading edge sweep angle of 45degrees. The tail's airfoil section, including a trailing edge rudder, is a NACA 0013 airfoil and its span is $2.80 \mathrm{~m}$. The baseline LGBB vehicle includes a swept canard, NACA 64A012 airfoil, located on the forward part of the fuselage. The vertical tail and canards, however, were not included in the geometry tested in the present study to simplify the application of the thin-film gauges (discussed below).

\section{Experimental Methods}

\section{A. Test Facility}

The 20-Inch Mach 6 Air Tunnel is a blowdown facility in which heated, dried and filtered air is used as the test gas. The tunnel has a two-dimensional, contoured nozzle which opens into a $0.5207 \mathrm{~m}$ by $0.508 \mathrm{~m}$ test section. The tunnel is
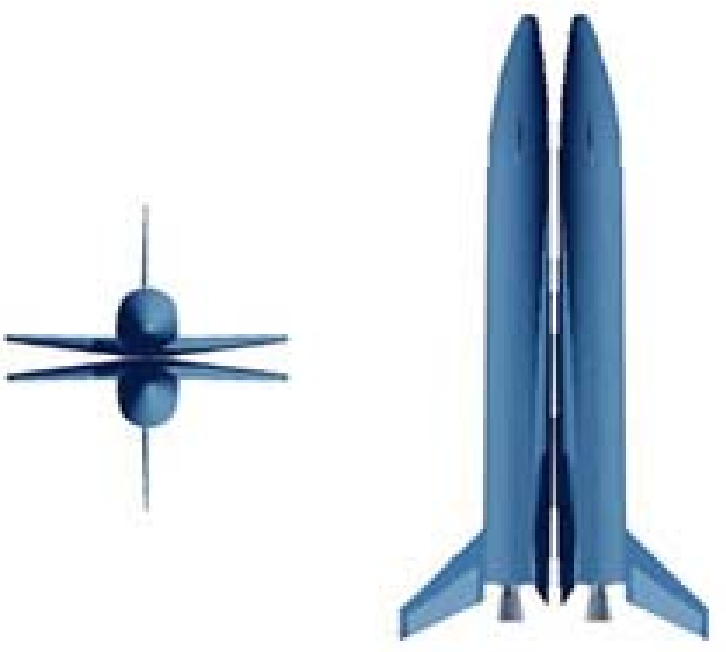

Figure 1. LGBB bimese arrangement

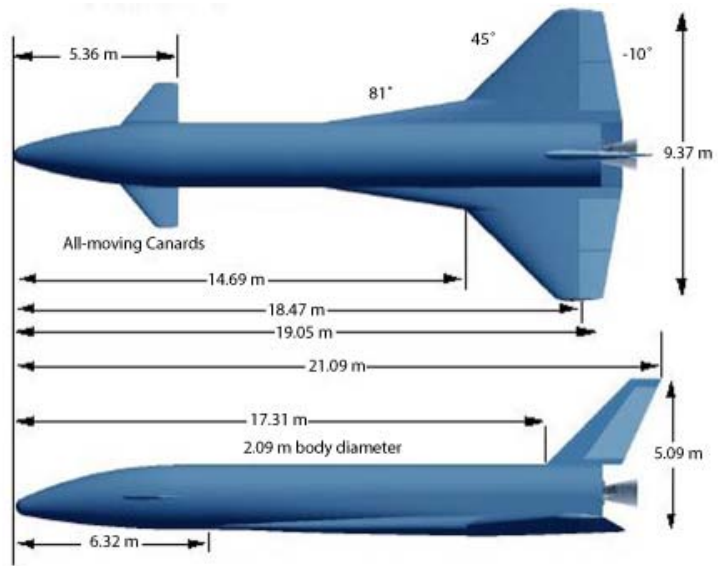

Figure 2. Dimensions of the LGBB vehicle. 
equipped with a bottom-mounted injection system that can transfer a model from the sheltered model box to the tunnel center-line in less than 0.5 seconds. Run times of up to 15 minutes are possible in this facility, although for the current aeroheating study run times of only a few seconds were required. The nominal reservoir conditions of this facility are stagnation pressures of $206.8 \mathrm{kPa}$ to $3447.4 \mathrm{kPa}$ with stagnation temperatures of $422.2 \mathrm{~K}$ to $555.5 \mathrm{~K}$, in which the freestream and post-shock flow behaves as a perfect gas $(\gamma \approx 1.4)$ with Mach numbers between 5.8 and 6.1 and Reynolds numbers of $1.64 \times 10^{6} / \mathrm{m}$ to $23.95 \times 10^{6} / \mathrm{m}$. The nominal flow conditions for this study are presented in Table 1. A more detailed description of this facility is presented in Ref. 3.

Table 1. Nominal flow conditions for the 20-Inch Mach 6 Air Tunnel for present study.

\begin{tabular}{cccccccc}
\hline \hline$R e_{\infty}(1 / \mathrm{m})$ & $M_{\infty}$ & $p_{t}\left(\mathrm{~N} / \mathrm{m}^{2}\right)$ & $T_{t}(\mathrm{~K})$ & $\rho_{\infty}\left(\mathrm{kg} / \mathrm{m}^{3}\right)$ & $U_{\infty}(\mathrm{m} / \mathrm{s})$ & $H_{t}(\mathrm{~J} / \mathrm{kg})$ & $h_{F R}$ \\
\hline $8.2789 \mathrm{E}+06$ & 5.9511 & $1.0533 \mathrm{E}+06$ & 503.15 & $3.9408 \mathrm{E}-02$ & 942.23 & $5.0612 \mathrm{E}+05$ & 0.9413 \\
\hline \hline
\end{tabular}

\section{B. Test Model Description}

Cast ceramic test models were used in the present study due to the speed and cost effectiveness at which they can be produced. In order to manufacture the ceramic test models, rapid-prototype, stereolithographic resin models were first fabricated based on surface geometry definitions in electronic data files. Wax molds of the resin models were made, and then a patented ${ }^{4}$ silica ceramic slip casting technique was used to form ceramic shells of the models. The shells were then back-filled with a hydraulically setting magnesia ceramic for strength and support. The cast ceramic aeroheating models were 0.0121 -scale representations of the LGBB (models were $0.23 \mathrm{~m}$ long).

\section{Test Techniques}

Although the primary test technique of the present study was a hybrid thin-film resistance gage technique, limited measurements were made using the technique of global phosphor thermography. These techniques are described below:

\section{Phosphor Thermography Technique}

For two of the cast ceramic models, global surface heating distributions were measured using the global optical method of two-color, relative-intensity, phosphor thermography ${ }^{5-8}$. The ceramic wind tunnel models were coated with a phosphor compound that fluoresces in two separate regions (green and red) of the visible light spectrum. During a wind tunnel run, the phosphor-coated model is illuminated by ultraviolet (UV) light sources, and the resulting fluorescent intensity of the model is recorded and digitized through a color CCD (charge coupled device) camera. The fluorescent intensity is dependent on both the intensity of the incident UV light and the local model surface temperature. The incident UV intensity dependence is removed by taking the ratio of the red to green intensity images, from which surface temperature distributions can be determined through prior calibrations. Images are acquired before the wind tunnel run and after injection of the model to the tunnel centerline during a run. Global heat transfer distributions are then computed from these temperature data using one-dimensional, semi-infinite solid, constant heat-transfer coefficient conduction theory ${ }^{8}$.

\section{Thin-Film Resistance Gauge Technique}

The global phosphor thermography technique could not be used to measure heating rates between the two vehicles because of line of sight restrictions. Therefore, a thin-film instrumented model was fabricated in a similar manner to that of Ref. 9. As stated above, cast ceramic models, usually used in phosphor thermographic aeroheating studies, were used in the present study. A thin polyimide film was then used as a transfer medium to place the gauges down on the vehicle surface. The thin-film gauges were etched onto the flat polyimide film, and the film was later bonded to the vehicle surface. The polyimide film that was chosen was a $5.08 \times 10^{-5} \mathrm{~m}$ thick type S Upilex ${ }^{\circledR}$ film. (Upilex is a registered trademark of Ube Industries, Ltd.)

The thin-film gauge layout is presented in Fig. 3. A long row of 44 gauges, spaced $5.08 \mathrm{~mm}$ apart, was placed along the vehicle centerline. Gauges were also placed symmetrically about the centerline on the upper and lower sur- 
faces of the wings. On each surface of the wings, a total of 13 gages were placed in 3 rows. A total of 96 gages were applied to the thin-film model.

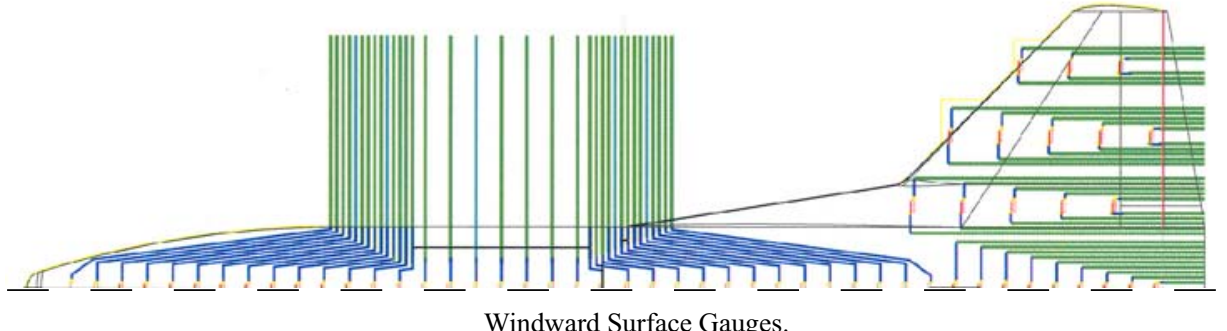

Windward Surface Gauges.

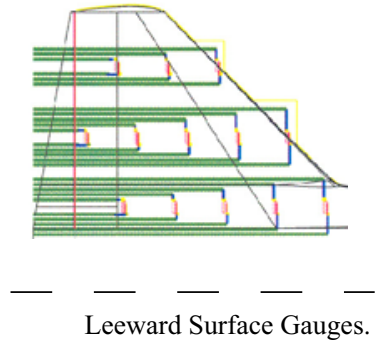

Figure 3. Thin-film gauge layout.

To facilitate the application of the gauges onto the ceramic model, the film panel was split into five separate panels (centerline and each surface of the wings). An adhesive was then used to bond the panels to the ceramic substrate one at a time. Each panel was positioned on the model, which was then placed in a plastic vacuum bag to mold the film to the model surface. As the air was suctioned from the bag, the panel was monitored to make sure it was located in the correct position and orientation. After this portion of the panel application was complete, the model with the newly applied panel was taken out of the vacuum bag and the panel was smoothed further to take out any adhesive or air bubbles under the panel. Any excess adhesive was removed.

The application of the film panels turned out to be more of an art than a science. The process of applying all five panels onto the model resulting in a satisfactory surface fidelity (no gaps at the split lines or waves in the panels) took approximately eight months since unsatisfactory panel applications had to be removed from the ceramic surface, which was carefully cleaned, and reapplied until the panel bond was acceptable.

\section{Data Reduction}

\section{Phosphor Thermography Technique}

One-dimensional, semi-infinite solid heat conduction theory ${ }^{8}$ was used to compute surface heating distributions from the global surface temperature data acquired through the technique of two-color, relative-intensity, phosphor thermography. A constant heat-transfer coefficient is assumed in this theory, and empirical corrections ${ }^{8}$ are made to account for changes in model substrate thermal properties with temperature. Phosphor images were acquired shortly after injection of the model to the tunnel centerline, which requires less than one second.

Data were extracted in the IHEAT $^{7}$ software package axially along the centerline. Results are presented herein in terms of a non-dimensional heat transfer coefficient ratio, $h / h_{F R}$, where $h_{F R}$ is the theoretical stagnation point heating to a $3.44 \times 10^{-3} \mathrm{~m}$ radius sphere (the nose radius of the test models) computed using the method of Fay-Riddell ${ }^{10}$ for a wall temperature of $300 \mathrm{~K}$.

\section{Thin-Film Resistance Gauge Technique}

A calibration was performed on the thin-film model (gauges already applied to ceramic model) over a temperature range of 291-395 K. The model was placed in an oven and allowed to come to a steady temperature in approximately 10 degree increments. The millivolt output of each gauge was recorded and then plotted vs. the temperature to back out a gauge calibration curve fit. Ordinarily, a second-order curve fit is used to convert the millivolt output of the gauges to temperature. However, in the temperature range tested in the present study, a linear fit was all that was necessary due to the linearity of the millivolt-temperature response.

Data reduction was performed using the code $1 \mathrm{DHEAT}^{11}$. The finite volume implementation of 1DHEAT takes direct account of the variable substrate thermal properties and removes the restriction of a semi-infinite substrate (thus allowing for a multiple layer analysis). This was important because of the dual layer of Upilex and ceramic on this model. Thus, heat transfer was computed using the finite volume technique, with 50 points in the Upilex layer $\left(5.08 \times 10^{-5} \mathrm{~m}\right.$ thick $)$ and 150 points in the ceramic layer $\left(6.35 \times 10^{-3} \mathrm{~m}\right.$ thick $)$. The current analysis has been conducted with the assumption that the approximately $25.4-\mu \mathrm{m}$ bond-line was negligible. Reliable thermal property information for the high-temperature epoxy used was not available. 


\section{E. Error Analysis}

\section{Phosphor Thermography Technique}

The estimated experimental uncertainty in heat transfer of the thermographic phosphor system is a function of model injection time, substrate thermal properties, initial wall temperature, run-time wall temperature, and fluorescence intensity. For higher model surface temperatures (greater than $400 \mathrm{~K}$ ), such as those on most of the windward surface, the total (bias and precision) uncertainty ${ }^{8}$ is approximately $\pm 8 \%$ to $\pm 10 \%$, while for lower temperatures (less than $325 \mathrm{~K}$ ), the total uncertainty is approximately $\pm 15 \%$ to $\pm 20 \%$. Additional measurement uncertainty can be introduced due to heat conduction in high-gradient regions such as the leading edge of the LGBB.

Uncertainties can be introduced when extracting line cut data from an image due to perspective distortion of the image, lack of pixel resolution in high-gradient regions, and lack of precision in locating fiducial marks. These errors are estimated to be less than $\pm 5 \%$ on relatively flat surfaces and up to $\pm 10 \%$ on highly curved surfaces.

A square root of the sum-of-the-squares estimate for the total uncertainty based on the above factors gives a worst-case experimental uncertainty range of $\pm 13 \%$ on flat areas experiencing high heating to $\pm 25 \%$ on curved areas with little heating. Since the test model in the present study is at $\alpha=0$-deg. for all runs (except for two test technique comparison runs), the total uncertainty of the phosphor thermography technique for the present study is on the order of $\pm 15 \%$.

\section{Thin-Film Resistance Gauge Technique}

Primary contributions to the uncertainty in the heat-transfer results for the thin-film resistance sensors include the uncertainties associated with the thermal properties of the substrate material. This includes both the neglected bond layer and the porous ceramic sub-layer which absorbed some of the adhesive. For traditional thin-film studies ${ }^{3}$, 11-13, the data is believed to be accurate to within $8-10 \%$ in regions where one-dimensional heat conduction can be assumed. The uncertainty levels for the thin-film resistance gage model of the present study should be higher than for the traditional techniques, as the thermal properties of the bond line and ceramic/adhesive sub-layer are not accurately known. Assuming the bond layer introduced a 1\% error and the thermal properties of the ceramic sub-layer did not change by any more than $15 \%$, a square root of the sum-of-the-squares estimate for the total uncertainty gives $\pm 20 \%$.

\section{F. Test Matrix and Tunnel Conditions}

The data were collected on the LGBB models at angles-of-attack of 0-, 20-, and 30-deg with a singe model for comparison between the two test techniques and at $\alpha=0$-deg for the bimese configuration. In the bimese configuration, a phosphor model was tested opposite to the thin-film model. Two geometric separation parameters were tested in the present study (see Fig. 4): $\Delta z$ was the distance between the lower surfaces of the vehicles; $\Delta x$ was the axial distance between the noses of the vehicles. All geometric separations are given with respect to the thin-film model (i.e. if the thin-film model is 5-in. behind the phosphor model, $\Delta x=-5$-in.). Therefore, if the value of $\Delta x$ is negative, the centerline data presented is for the booster. In the present study, $\Delta z$ varied from 0.5 -in. to 3 -in. and $\Delta x$ varied from -5in. to +6 -in (both positive and negative values of $\Delta x$ were tested to obtain both booster and orbiter heating data). A constant Reynolds number of $8.28 \times 10^{6} / \mathrm{m}$ was run to be consistent with the Reynolds number tested in Ref. 1 in the 20-Inch Mach 6 Air Tunnel. A total of 90 runs were performed in a two week tunnel entry.

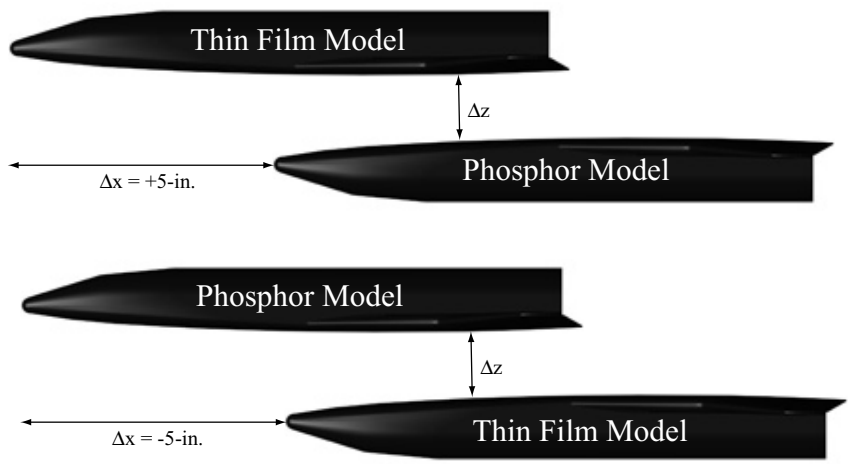

Figure 4. Model separation parameters. 


\section{Experimental Results}

\section{A. Test Technique Comparison}

A comparison between the test techniques of phosphor thermography and the hybrid thin-film resistance gage technique is included because the thin-film technique used is not a mature technology in comparison with standard thin-film techniques. This technique was chosen because the models could be fabricated quickly and were inexpensive. The comparison is presented in Fig. 5 for angles-ofattack of 0-, 20-, and 30-degrees. The 20- and 30-deg. angles-of-attack are included to extend the comparison of the two test techniques beyond the low heating levels experienced at $\alpha=0$-deg to levels comparable to those experienced due to shock interactions in the present study. The thin-film data is approximately $40 \%$ lower than the phosphor thermography data. This is believed to be partially due to the uncertainty in the substrate thermal properties, but was not fully understood as of the writing of this paper. This discrepancy is still being investigated. Because of the uncertainty in the heating rates, centerline heating measurements will be presented herein as a ratio of the heating rates measured during a run to the heating rates measured on a baseline, single model run. Therefore, if the heating ratio is equal to 1.0 , the heating rate measured at a specific gage was equal to the heating rate at the same gauge from the baseline run.

\section{B. Windward Heating}

Centerline heating augmentations for the bimese configuration are presented in Figs. 6-17, along with corresponding schlieren images for the closest separation value at each axial offset. This series of figures begins with the thin-film model 6-in. in front of the phosphor model (data from orbiter) and decreases in increments of 1 -in. to the thin-film model 5-in. behind the phosphor model (data from booster). In each of these plots, the model separation $(\Delta z)$ begins at 0.5 -in. and increases in 0.5 -in. increments up to 3.0-in. Each plot includes a sketch of the model orientation. The thin-film model is labeled as either the orbiter or booster in each figure. The legend for this series of figures can be seen in Table 2. In general, as the vehicles separated ( $\Delta z$ increased), the heating augmentation decreased.

Data and a schlieren image for $\Delta x=0$-in. are presented in Fig. 12. A reflected shock train can be seen between the two vehicles resulting from the bow shocks. The initial bow shock impingement from the opposite vehicle (for the closest separation) was located at approximately $x / L=$ 0.30 . The first reflected shock impingement is located at approximately $x / L=0.50$. Finally, a third shock impingement can be seen at approximately $x / L=0.70$. These impingement locations correlate well with the schlieren image.

When considering the orbiter, the initial shock interaction from the booster moved aft with increasing $\Delta x$ and the magnitude of the resulting surface heating increased. The interaction of the bow shocks moved towards the nose of the booster, which changed the angle at which the booster bow shock impinged on the orbiter, thus changing the
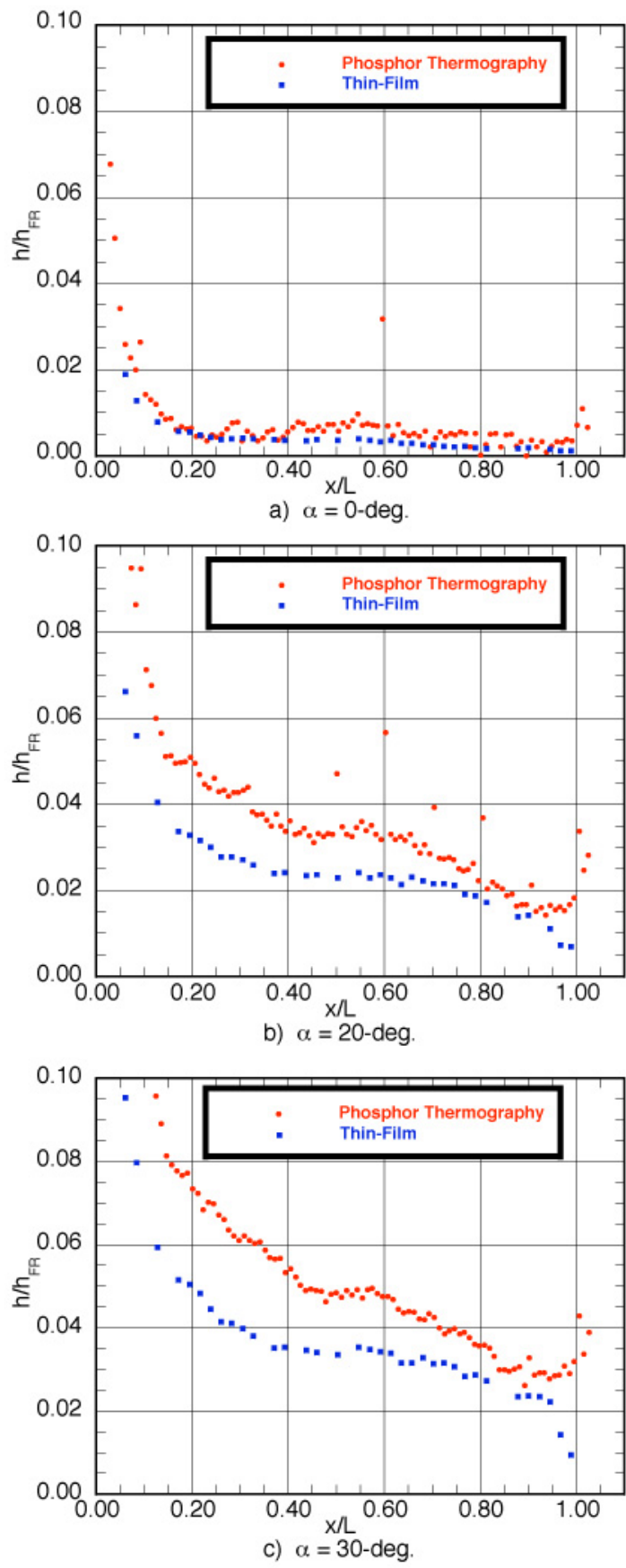

Figure 5. Comparison of test techniques at $\alpha=0$-, 20-, and 30-deg. 
nature of the shock, boundary layer interaction. As the booster bow shock moves aft, the separation region in front of the shock impingement can be seen to increase in size (area of decreased heating immediately before increase in heating). The largest deviations from the baseline, single model heating distribution occurred at the greater axial separations. At $\Delta x=+6$-in., heating rates increased by as much as 13-times toward the aft end of the model due to the interaction with the bow shock from the booster. It also appears that at the greater axial offsets, the bow shock from the booster is also interacting with the shock off of the chine and wing of the orbiter, which could further increase heating levels.

When considering the booster, the initial bow shock impingement moved forward as $\Delta x$ decreased and the magnitudes of the impingements decreased. The largest deviation from the baseline heating distribution experienced was when the booster and orbiter were even with each other $(\Delta x=0$-in.). In this configuration, both vehicles experienced heating augmentations of approximately 6-times what the baseline configuration experienced. As the axial separation between the booster and orbiter increased, the heating augmentation decreased over the centerline of the booster.

Table 2. Centerline augmentation legend.
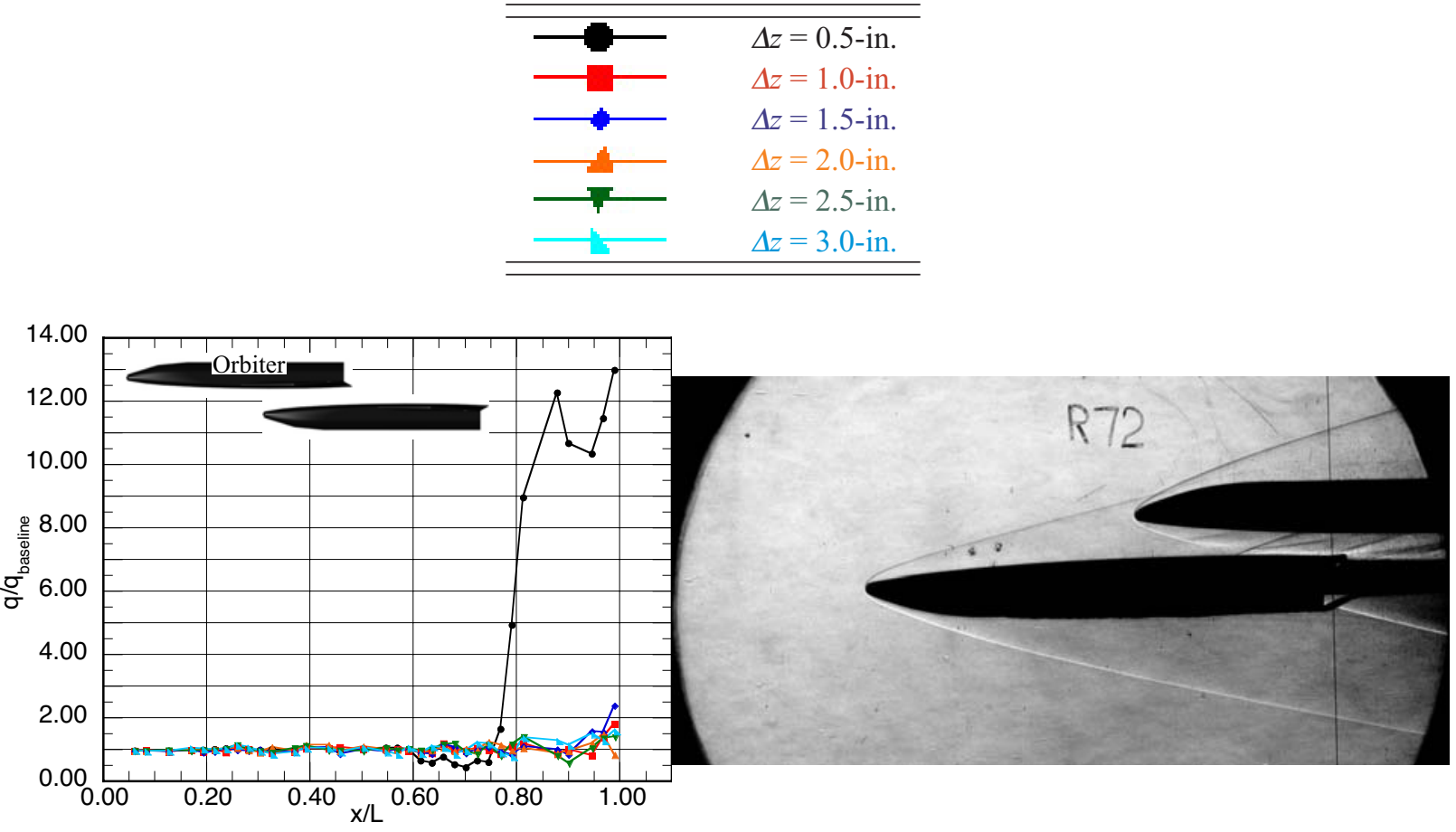

Figure 6. Windward centerline heating augmentation on the orbiter at $\Delta x=+6$-in.

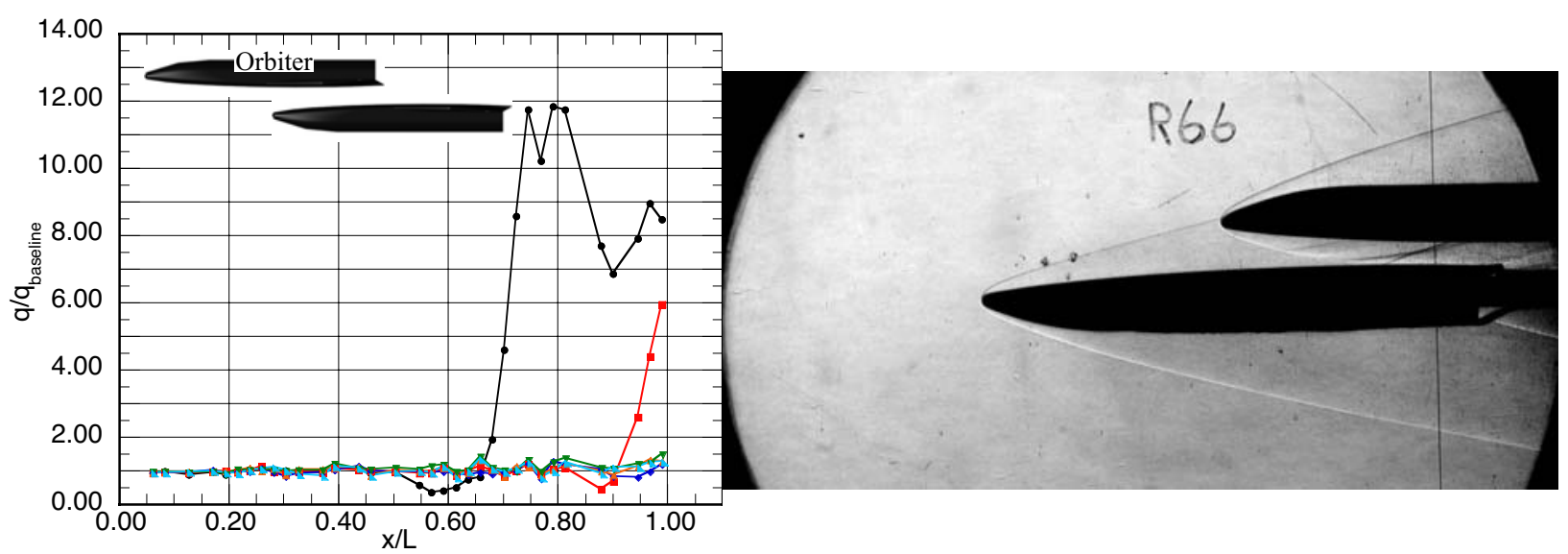


Figure 7. Windward centerline heating augmentation on the orbiter at $\Delta x=+5$-in.

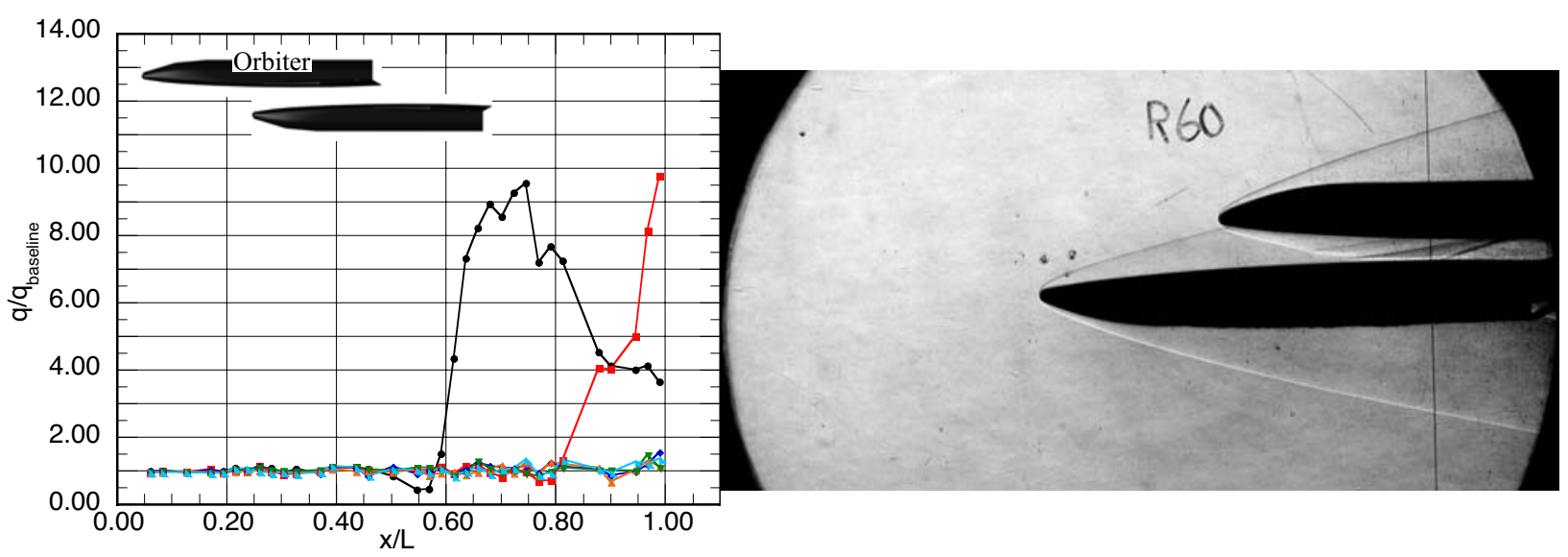

Figure 8. Windward centerline heating augmentation on the orbiter at $\Delta x=+4$-in.

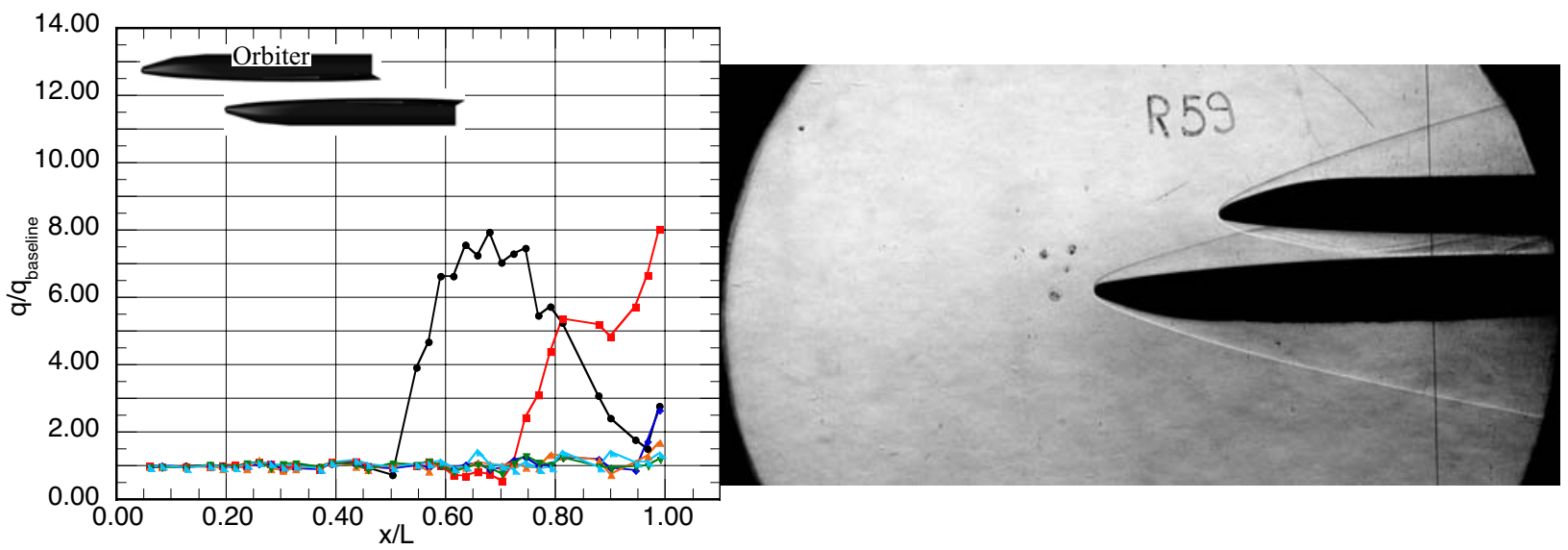

Figure 9. Windward centerline heating augmentation on the orbiter at $\Delta x=+3$-in.

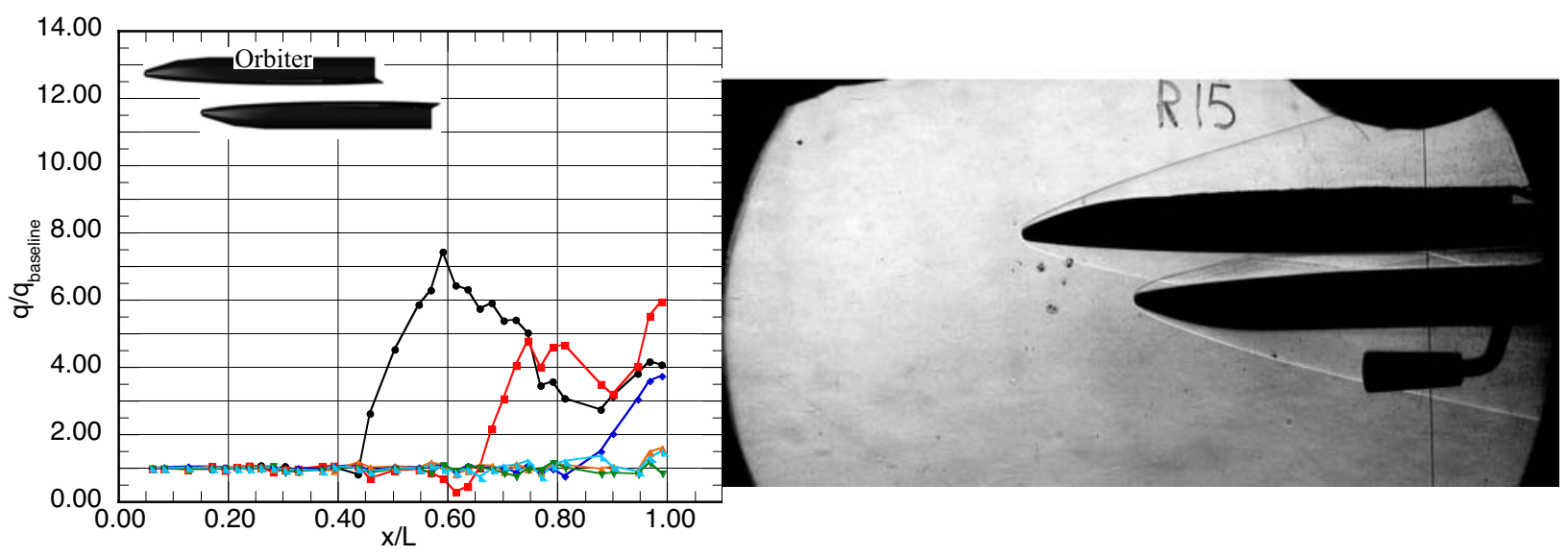


Figure 10. Windward centerline heating augmentation on the orbiter at $\Delta x=+2$-in.

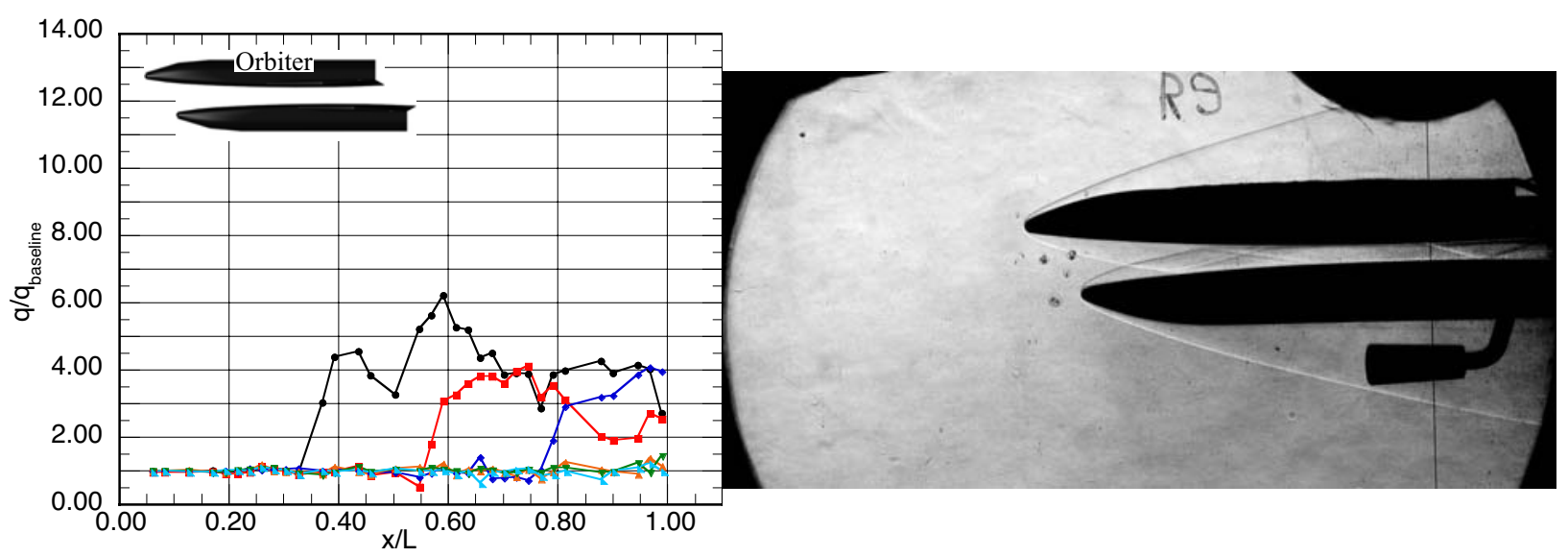

Figure 11. Windward centerline heating augmentation on the orbiter at $\Delta x=+1$-in.

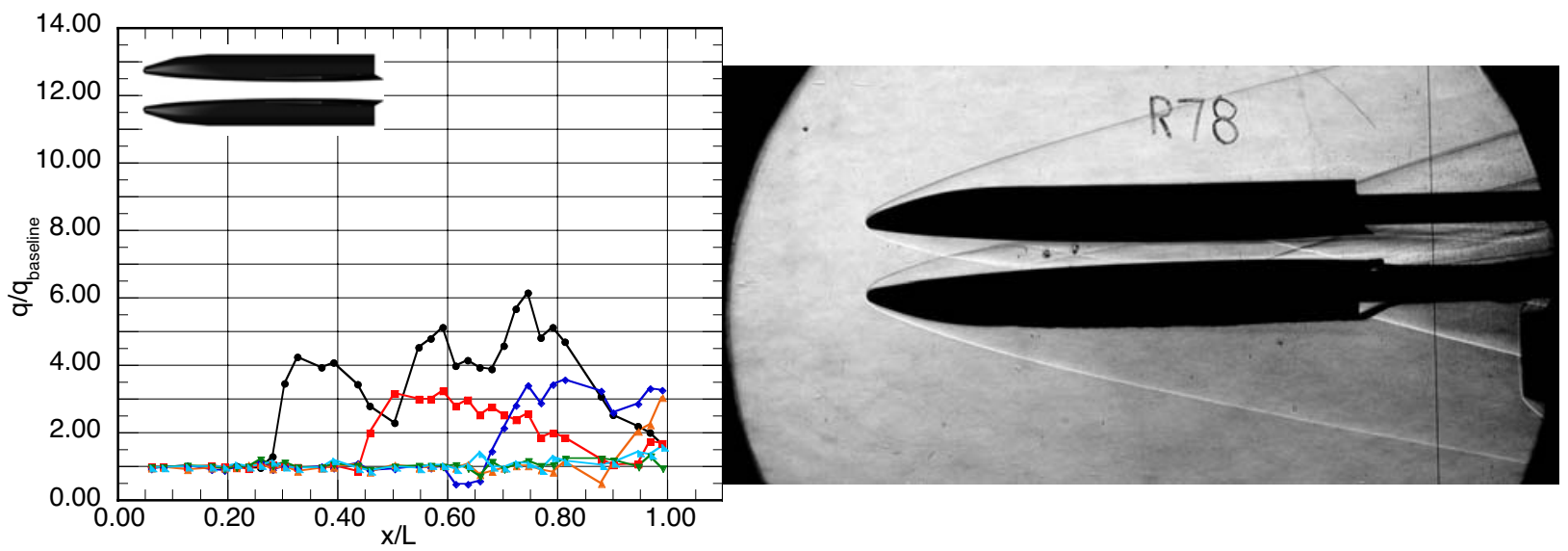

Figure 12. Windward centerline heating augmentation at $\Delta x=0$-in.

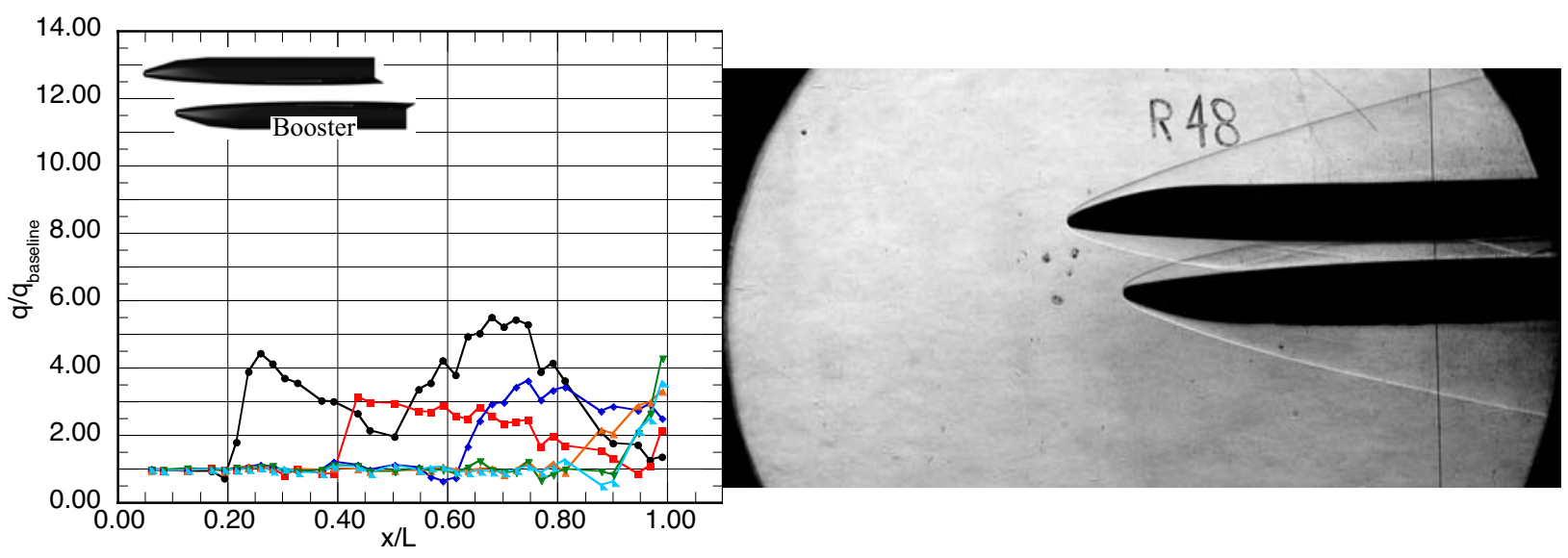


Figure 13. Windward centerline heating augmentation on the booster at $\Delta x=-1$-in.

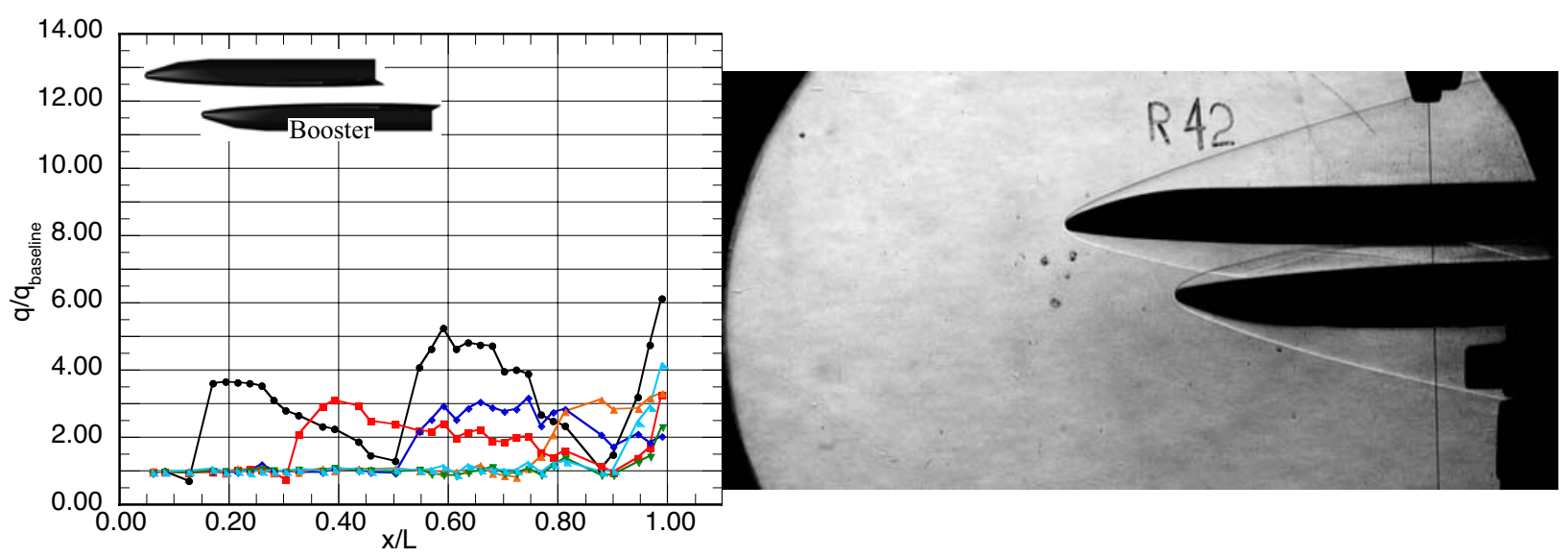

Figure 14. Windward centerline heating augmentation on the booster at $\Delta x=-2$-in.

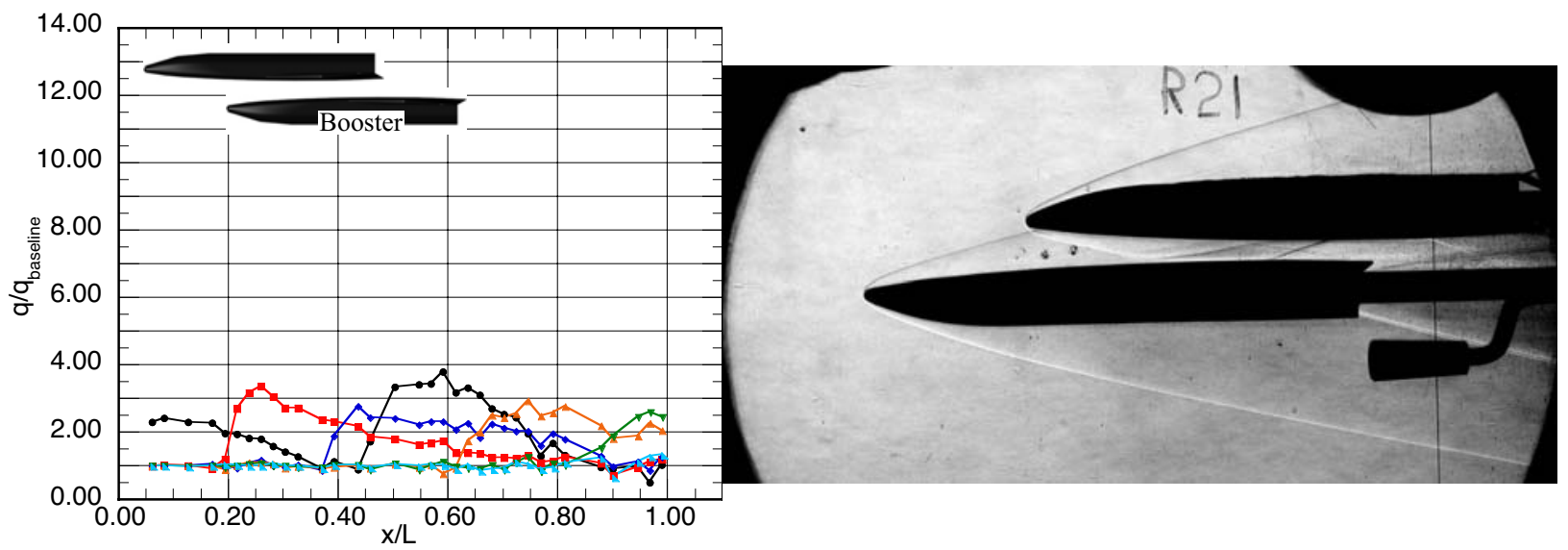

Figure 15. Windward centerline heating augmentation on the booster at $\Delta x=-3$-in.

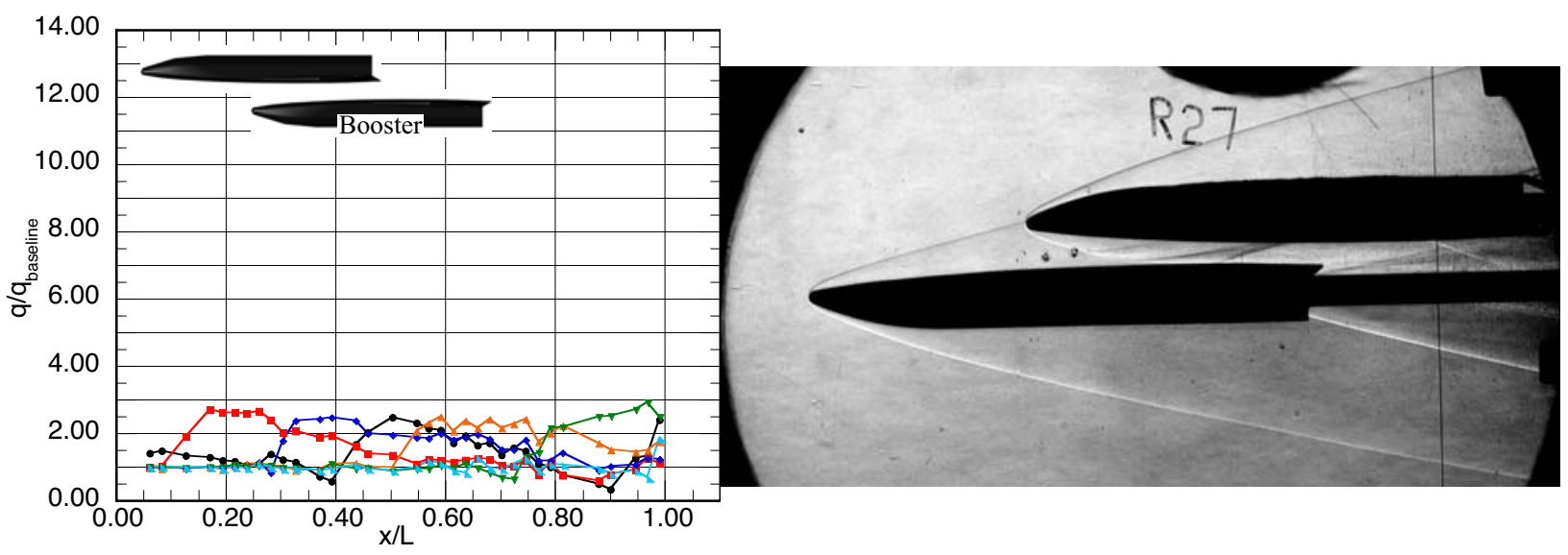


Figure 16. Windward centerline heating augmentation on the booster at $\Delta x=-4$-in.

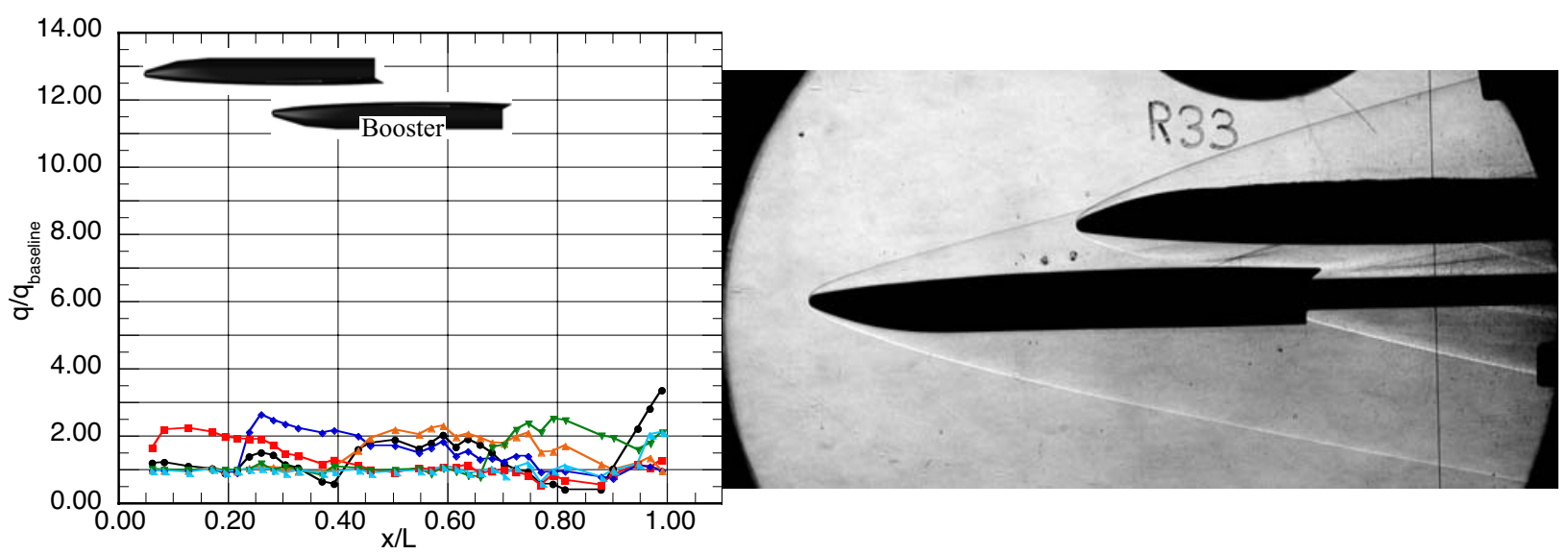

Figure 17. Windward centerline heating augmentation on the booster at $\Delta x=-5$-in.

\section{Leeward Heating.}

Global phosphor thermography images of the leeward surface from the $\Delta x=+6$-in. bimese configuration are presented in Fig. 18 with the corresponding schlieren images in Fig. 19. At this location, the phosphor model was 6-in. behind the thin-film model (phosphor model was the booster), so the phosphor model experienced the greatest range of possible shock interactions as the thin-film model separated away from it. Most of the leeward surface saw no change in heating levels as the booster was moved away from the orbiter. It is believed that at the lower separation distances, the orbiter bow shock layer feeds the leeside flow of the booster (Fig. 19.a). At separations of 1.5 and 2.0in., a slight increase in heating was observed along the upper surface of the body near the aft extending from the beginning of the wing chine to the aft of the vehicle. It is believed that this increase is due to the interaction of the wing and bow shock of the thin-film model, respectively, and the orbiter shock layer no longer feeds the upper surface flowfield.

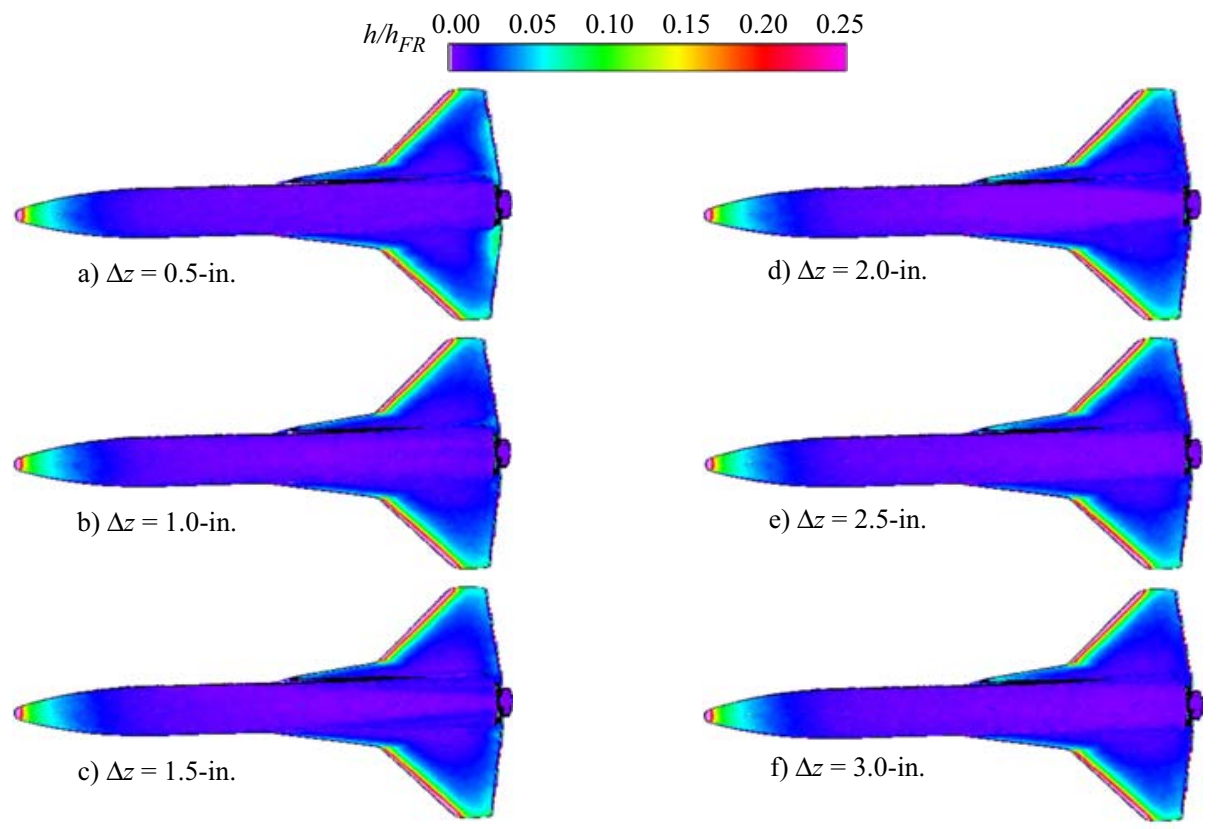

Figure 18. Leeward global aeroheating on the booster at $\Delta x=+6$-in. 


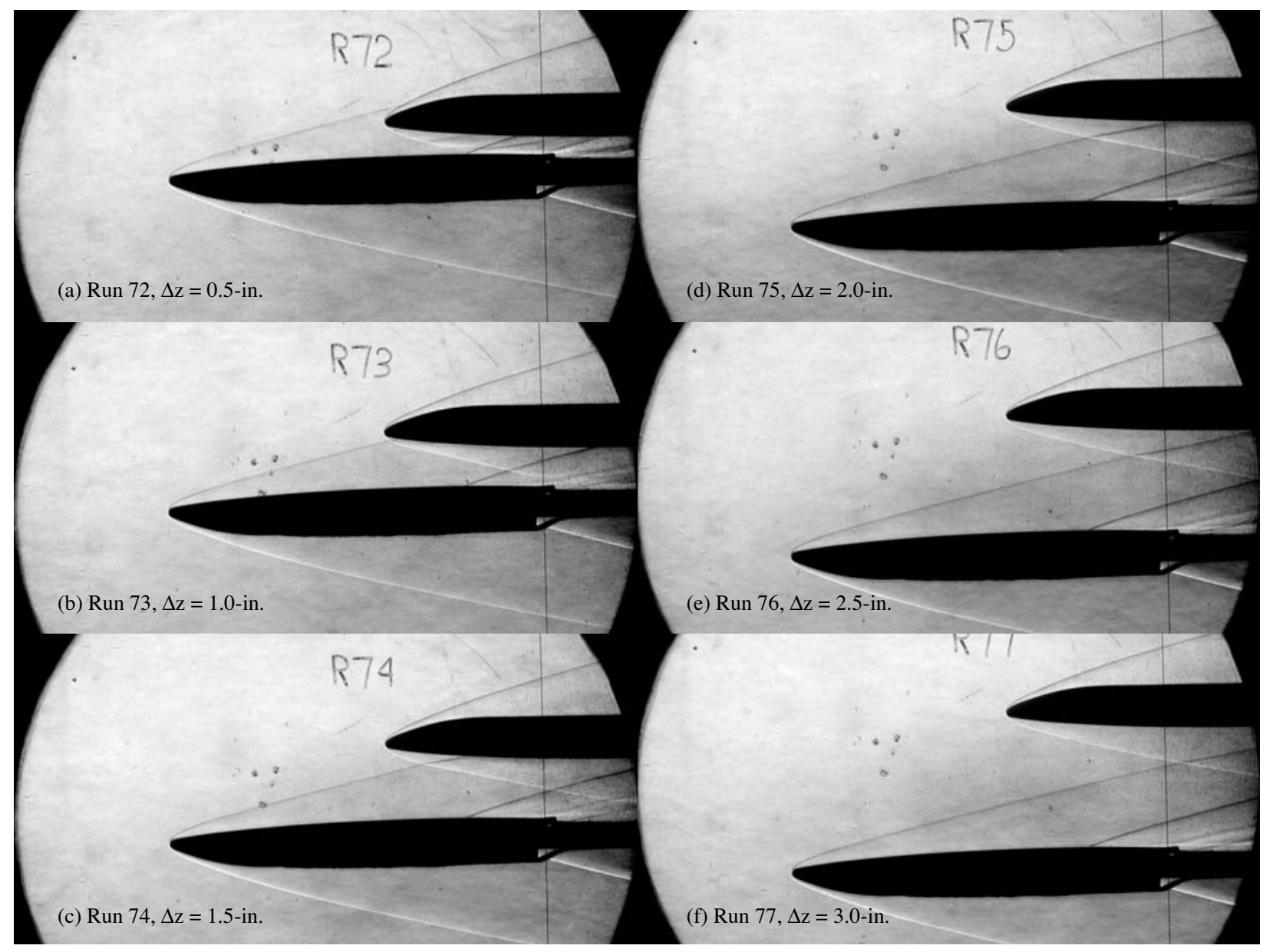

Figure 19. Schlieren images at $\Delta x=+6$-in.

\section{Conclusion}

An experimental aeroheating study was conducted in the NASA Langley 20-Inch Mach 6 Air Tunnel on a generic bimese two-stage-to-orbit configuration. This test was conducted in part to study the effects of shock interactions between a booster and an orbiter of comparable size. It was found that, as the orbiter moved ahead and away from the booster, heating levels along the centerline of the orbiter were augmented by as much as 13-times the value experienced on baseline, single model. The booster experienced heating augmentations of as much as 6-times the baseline, single model configuration. The leeward surface of the vehicles did not experience any significant changes in heating levels as the vehicles separated. The database developed can now be used for computational fluid dynamic code validation. The present study also evaluated a new hybrid, multi-layer, thin-film gauge technique. It was found that the complexities in gauge application and uncertainties in substrate thermal properties outweighed the advantages of quick model fabrication and lower cost as compared to traditional thin-film techniques.

\section{Acknowledgements}

The author would like to acknowledge the contributions of the following individuals to this research: Vincent Cruz for thin-film application; Johnny Mau for thin-film layout design; Harry Stotler, Grace Gleason, and Roland Hatten for operation of the 20-Inch Mach 6 Air Tunnel and data acquisition support; Mike Powers and Mark Griffith for fabrication of the ceramic test models; and Edward Covington and Pete Veneris for model fidelity measurements and fiducial mark placement. 


\section{References}

${ }^{1}$ Murphy, K. J., Buning, P. G., Pamadi, B. N., Scallion, W. I., and Jones, K. M., “Overview of Transonic to Hypersonic Stage Separation Tool Development for Multi-Stage-To-Orbit Concepts," AIAA Paper 2004-2595, July 2004.

${ }^{2}$ NGLT Fact Sheet, http://www1.msfc.nasa.gov/NEWSROOM/background/facts/ngltfacts.pdf, Nov. 2003.

${ }^{3}$ Micol, J.R., "Hypersonic Aerodynamic/Aerothermodynamic Testing Capabilities at Langley Research Center: Aerothermodynamic Facilities Complex,” AIAA Paper 95-2107, June 1995.

${ }^{4}$ Buck, G.M., and Vasques, P., “An Investment Ceramic Slip-Casting Technique for Net-Form, Precision, Detailed Casting of Ceramic Models,” U.S. Patent 5,266,252, November 1993.

${ }^{5}$ Buck, G.M., “Automated Thermal Mapping Techniques Using Chromatic Image Analysis,” NASA TM 101554, April 1989.

${ }^{6}$ Buck, G.M., "Surface Temperature/Heat Transfer Measurement Using a Quantitative Phosphor Thermography System," AIAA Paper 91-0064, January 1991.

${ }^{7}$ Merski, N.R., “A Relative-Intensity, Two-Color Phosphor Thermography System,” NASA TM 104123, September 1991.

${ }^{8}$ Merski, N.R., “An Improved Two-Color Relative-Intensity Phosphor Thermography Method For Hypersonic Wind Tunnel Aeroheating Measurements," NASA CDTP-1017, February 2001.

${ }^{9}$ Berry, S. A., and Nowak, R. J., "Fin Leading-Edge Sweep Effect on Shock-Shock Interaction at Mach 6," Journal of Spacecraft and Rockets, Vol. 34, No. 4, July-Aug. 1997, pp 416-425.

${ }^{10}$ Fay, J.A., and Riddell, F.R., "Theory of Stagnation Point Heat Transfer in Dissociated Air," Journal of Aeronautical Sciences, Vol. 25, No. 2, 1958, pp. 73-85.

${ }^{11}$ Hollis, B. R., "User's Manual for the One-Dimensional Hypersonic Experimental Aero-Thermodynamic (1DHEAT) Data Reduction Code," NASA CR-4691, Aug. 1995.

${ }^{12}$ Miller, C. G., "Comparison of Thin-Film Resistance Heat-Transfer gages with Thin-Skin Transient Calorimeter Gages in Conventional Hypersonic wind Tunnels,” NASA TM 83197, Dec. 1981.

${ }^{13}$ Miller, C. G., Micol, J. R., and Gnoffo, P. A., "Laminar Heat-Transfer Distributions on Biconics at Incidence in Hypersonic-Hypervelocity Flows," NASA TP 2213, 1984. 